\title{
Micropropagation in vitro of essential oil rose hybrids obtained in embryoculture
}

\author{
Natalia Yegorova*, Irina Stavtzeva, Victor Zolotilov \\ Research Institute of Agriculture of Crimea, 295493 Simferopol, Russia
}

\begin{abstract}
The aim of the work was to study the features of clonal micropropagation of essential oil rose interspecific hybrids obtained in embryo culture in vitro. Analysis of 12 crossing combinations demonstrated that the frequency of hybrid seedling formation in the embryo culture varied from 0 to $71.4 \%$. For clonal micropropagation obtained in vitro seedlings were divided into stem segments with a node and cultivated on MS culture medium supplemented with $0.5 \mathrm{mg} / \mathrm{l} \mathrm{BAP}$ and $0.1 \mathrm{mg} / \mathrm{l} \mathrm{GA}$. During the multiplication of 13 hybrids $(R$. alba $\times R$. damascena cv. 'Kazanlykskaya') in 2-6 subcultures, high variability of the multiplication index (1.8-18.5 depending on the genotype and passage) was revealed. This parameter was maximum in the $3-4^{\text {th }}$ subcultures. The best ability to micropropagation showed hybrid No. 37-14. Microshoots were rooted in vitro on $1 / 2$ MS medium, containing for different hybrids 0.5 or $1.0 \mathrm{mg} / \mathrm{l} \mathrm{NAA}$; frequency - up to 80.5-100.0\%. However, in No. 37-2, 37-19 and 37-31 on four tested media, the number of shoots with roots was only $0-35.4 \%$.
\end{abstract}

\section{Introduction}

One of the oldest aromatic plants cultivated mainly in the East and the Mediterranean countries is the essential oil rose. To obtain essential oil, most often Rosa damascena Mill., $R$. moschata Herrm., $R$. gallica Linn., $R$. centifolia Linn., $R$. bourboniana Desportes., $R$. alba Linn. and $R$. chinensis Jacq. are grown [1]. Essential oil and other products of rose processing are actively used in perfumery, cosmetics, food industry. In medicine, they are used for the treatment of cardiovascular disorders, mouth and throat diseases, gastritis, cholecystitis, ulcers, etc. [2, 3].

Most of the essential oil rose cultivars grown in Russia were created using interspecific hybridization [4]. Nowadays, obtaining hybrids that combine resistance to abiotic and biotic stresses with high content and quality of essential oil is the most urgent issue. However, due to postgamous incompatibility, the death of embryos in remote rose crosses leading to a low yield of seeds is often observed [5]. To overcome this problem, a technique of obtaining essential oil rose hybrids by cultivating isolated embryos in vitro has been developed $[5,6]$.

At the same time, to increase the efficiency of breeding, it is important not only to obtain but also quickly propagate unique hybrid plants. For this, it is promising to use the

\footnotetext{
* Corresponding author: yegorova.na@mail.ru
} 
biotechnology of clonal micropropagation. In the literature, there is information about various aspects of the essential oil rose propagation in vitro. Most of the works are devoted to the optimization of culture media for the main stages of micropropagation [1]. In these studies, buds and meristems [7-9], stem segments with a node [7, 10-12] were usually used as explants. Concerning the composition of culture media, the data presented by different authors are rather contradictory. For rose propagation, researchers recommend media with the addition of 6-benzylaminopurine [7, 8, 10-12], thidiazuron [1], or cytokinin together with auxins ( $\alpha$-naphthaleneacetic acid, indole-3-acetic acid) or gibberellic acid $[1,9,13$, 14]. Furthermore, in some works, the effect of explant type and size $[1,11,13]$, isolation season $[8,15]$ and cultivation conditions in vitro (illumination $[1,2]$ or propagation system $[11,13,16])$ on the multiplication efficiency of essential oil rose were also studied. Many publications have pointed out the important role of genotype in rose propagation, however, only 2-3 cultivars or samples were studied $[9,14,15,17]$. Moreover, most often, various issues of propagation were studied using the species $R$. damascena $[2,7,10-12,14]$.

The aim of the work was to study the features of clonal micropropagation of essential oil rose interspecific hybrids obtained in embryo culture in vitro.

\section{Materials and Methods}

In our studies we used cultivars ('Lada', 'Lan', 'Raduga', 'Aura', 'Kazanlykskaya', 'Zolushka', 'Michurinka', 'Festival'naya') [4] and essential oil rose hybrids obtained with the participation of Rosa damascena Mill., $R$. gallica L. and $R$. alba L. species. Hybridization, in vitro introduction and embryo culture were carried out according to the previously developed technique [6].

The hybrid seedlings obtained in embryoculture $(R$. alba $\times R$. damascena cv. 'Kazanlykskaya') were propagated in vitro using as explants stem segments with a node. Explants were cultivated on the modified for roses micropropagation Murashige and Skoog culture medium (MS) with the addition of $1.0 \mathrm{mg} / \mathrm{l}$ 6-benzylaminopurine, $0.1 \mathrm{mg} / \mathrm{l}$ gibberellic acid and 2\% glucose [6]. For rooting shoots, the MS medium supplemented with $\alpha$-naphthaleneacetic acid (NAA), indole-3-butyric acid (IBA) (Sigma, USA) was used. Microcuttings were conducted every 40-45 days. Explants and shoots were kept at $26^{\circ} \mathrm{C}$, $70 \%$ of relative air humidity, under $16-\mathrm{h}$ photoperiod and $2-3 \mathrm{klx}$ illumination. At the end of each growing cycle, we determined the length and number of shoots, the number of nodes on the shoot, the frequency of rhizogenesis. The multiplication index was calculated as the number of microcuttings that can be obtained during one subculture. For this, the number of shoots formed on the explant was multiplied by the number of nodes on the shoot. Experiments on in vitro culture were carried out in three replications; at each variant, 20 (for embryoculture) or 10 (for micropropagation) explants were analyzed. The data are processed using the Microsoft Office software package (Excel 2007). The tables show the average values and their standard errors; the figure presents the average values and confidence intervals.

\section{Results and Discussion}

Using a previously developed technique [6], hybridization, isolation and cultivation of rose embryos in vitro were carried out. For this we used 12 crossing combinations. The frequency of seedling formation in embryoculture was influenced significantly by the genotype of parental forms (Table 1.). The maximum frequency of seedling formation (71.4\%) was observed when crossing 'Lada' and 'Kazanlykskaya' cultivars. This parameter 
was the smallest in the cross combination $R$. alba $\times$ 'Aura ' $(12.4 \%)$. When hybridizing No. 1993 and cv. 'Aura' no seedlings from cultured embryos were obtained.

It should be noted that in combinations with the highest $\%$ of seedling formation ('Lada' $\times$ 'Kazanlykskaya', $R$. alba $\times$ 'Michurinka', 'Raduga' $\times$ 'Kazanlykskaya', 'Festival'naya' $\times$ 'Raduga') shorter seedlings formed (on average 1.8-2.7 cm). At the same time, in the cross combinations that give a low seedling yield ('Zolushka' $\times$ 'Kazanlykskaya', 'Aura' $\times$ 'Raduga', 'Raduga' $\times$ 'Festival'naya'), their maximum length was revealed (4.4-4.5 cm). In a number of crossing combinations ('Zolushka' $\times$ 'Kazanlykskaya', 'Lada' $\times$ 'Kazanlykskaya', $R$. alba $\times$ 'Aura '), a weak root development in the seedlings was noted, as a result of which their average length was the shortest (1.7$2.2 \mathrm{~cm})$. In some seedlings, the roots were not formed. In other previously analyzed 23 hybrid combinations [6], the frequency of seedling formation in embryoculture usually did not exceed $9-34 \%$. The maximum seedling formation (up to 64.2-76.9\%) was revealed only when sample 8017 was used as the maternal form.

Table 1. Influence of the crossing combination on the frequency of formation and characteristics of hybrid seedlings in embryoculture of essential oil rose (30 days of cultivation)

\begin{tabular}{|c|c|c|c|}
\hline Crossing combination & $\begin{array}{l}\text { Frequency of } \\
\text { seedling } \\
\text { formation, \% }\end{array}$ & $\begin{array}{l}\text { Seedling length, } \\
\mathrm{cm}\end{array}$ & $\begin{array}{l}\text { Length of the } \\
\text { main root, cm }\end{array}$ \\
\hline R. alba $\times$ 'Kazanlykskaya' & $36.5 \pm 4.1$ & $2.5 \pm 0.2$ & $6.9 \pm 0.5$ \\
\hline 'Lada' x 'Kazanlykskaya' & $71.4 \pm 6.5$ & $1.8 \pm 0.2$ & $2.1 \pm 0.2$ \\
\hline 'Zolushka' × 'Kazanlykskaya' & $15.4 \pm 1.2$ & $4.5 \pm 0.3$ & $1.7 \pm 0.2$ \\
\hline 'Lan' × 'Kazanlykskaya' & $23.1 \pm 3.2$ & $2.2 \pm 0.2$ & $7.5 \pm 0.6$ \\
\hline 'Raduga' × 'Kazanlykskaya' & $51.5 \pm 4.9$ & $2.6 \pm 0.3$ & $3.6 \pm 0.3$ \\
\hline №1993 × 'Aura' & 0 & - & - \\
\hline R. alba $\times$ 'Michurinka' & $52.8 \pm 5.6$ & $2.7 \pm 0.3$ & $6.9 \pm 0.5$ \\
\hline R. alba $\times$ 'Aura ' & $12.4 \pm 1.4$ & $3.1 \pm 0.3$ & $2.2 \pm 0.2$ \\
\hline 'Aura ' $\times$ 'Raduga' & $13.7 \pm 1.5$ & $4.4 \pm 0.3$ & $7.7 \pm 0.6$ \\
\hline 'Zolushka' $\times$ 'Lada' & $41.1 \pm 4.5$ & $3.2 \pm 0.2$ & $7.5 \pm 0.6$ \\
\hline 'Festival'naya' × 'Raduga' & $48.3 \pm 5.0$ & $2.4 \pm 0.3$ & $6.6 \pm 0.5$ \\
\hline 'Raduga' × 'Festival'naya' & $19.2 \pm 2.0$ & $4.5 \pm 0.5$ & $4.7 \pm 0.4$ \\
\hline
\end{tabular}

In most crosses variants, a limited number of hybrid seedlings in vitro are usually developed. In the future, they can be adapted ex vitro, the plants can be transferred to the field and propagated by traditional methods for breeding research. However, for the rapid propagation of hybrids, it is advisable to use clonal micropropagation. In this case, microcutting obtained in embryoculture of test-tube plants can be carried out and multiplication can begin from the second propagation stage (actually micropropagation). This allows you to quickly obtain the necessary number of plants of each hybrid for further assessment of their economically valuable traits. This is especially important when obtaining seedlings with a poorly developed root, which can die during further adaptation.

Microcutting at the second stage can be carried out repeatedly to obtain the required number of plants; therefore, it is urgent to study the morphogenesis of explants during several subcultures. Morphometric parameters of explants of 13 hybrids $(R$. alba $\times R$. damascena cv. 'Kazanlykskaya') during long-term propagation in vitro were analyzed. During micropropagation, not only the forming of small adventive shoots were used for propagation, but also microcutting of the shoots with normal internodes was carried out. This allowed us to increase the multiplication index. A significant influence of the genotype 
within one crossing combination on the morphogenesis of developing in vitro explants was established. The number and length of shoots in the studied hybrids significantly varied. At the same time, induction of adventitious shoots practically did not occur in No. 37-8. Table 2 shows the change in the main parameter for micropropagation, multiplication index, during 2-6 subcultures. The obtained data indicate a significant variability of the multiplication index depending on the hybrid. So, in the second subculture, this parameter varied from 2.0 to 8.4 , and in the fourth - from 3.7 to 18.5 . The maximum multiplication index was noted in No. 37-14; the lowest - in No. 37-8.

Table 2. Effect of subcultures number on the multiplication index during micropropagation of essential oil rose hybrids ( $R$. alba $\times R$. damascena cv. 'Kazanlykskaya') obtained in embryoculture

\begin{tabular}{|c|c|c|c|c|c|}
\hline \multirow{2}{*}{ No. of hybrid } & \multicolumn{5}{|c|}{ Number of subcultures } \\
\cline { 2 - 6 } & 2 & 3 & 4 & 5 & 6 \\
\hline $37-2$ & $8.4 \pm 0.9$ & $9.5 \pm 0.8$ & $12.8 \pm 1.1$ & $7.8 \pm 0.8$ & $6.1 \pm 0.5$ \\
\hline $37-5$ & $4.2 \pm 0.4$ & $11.2 \pm 1.2$ & $15.7 \pm 1.6$ & $9.4 \pm 0.9$ & $6.4 \pm 0.7$ \\
\hline $37-8$ & $2.0 \pm 0.2$ & $2.7 \pm 0.3$ & $3.7 \pm 0.4$ & $2.1 \pm 0.2$ & $1.9 \pm 0.2$ \\
\hline $37-11$ & $7.0 \pm 0.5$ & $9.4 \pm 0.8$ & $9.5 \pm 1.0$ & $7.7 \pm 0.6$ & $6.8 \pm 0.6$ \\
\hline $37-14$ & $6.1 \pm 0.7$ & $13.1 \pm 1.2$ & $18.5 \pm 2.0$ & $10.3 \pm 1.2$ & $8.7 \pm 0.9$ \\
\hline $37-15$ & $4.2 \pm 0.3$ & $9.9 \pm 0.8$ & $6.4 \pm 0.6$ & $3.2 \pm 0.3$ & $3.1 \pm 0.3$ \\
\hline $37-19$ & $4.6 \pm 0.4$ & $9.6 \pm 0.9$ & $7.5 \pm 0.7$ & $4.4 \pm 0.5$ & $4.8 \pm 0.5$ \\
\hline $37-20$ & $7.0 \pm 0.8$ & $10.8 \pm 1.0$ & $10.3 \pm 1.2$ & $8.4 \pm 0.8$ & $7.5 \pm 0.7$ \\
\hline $37-21$ & $6.8 \pm 0.5$ & $11.7 \pm 1.1$ & $9.1 \pm 0.8$ & $6.5 \pm 0.7$ & $5.8 \pm 0.6$ \\
\hline $37-24$ & $6.1 \pm 0.6$ & $10.8 \pm 0.8$ & $7.3 \pm 0.7$ & $5.5 \pm 0.5$ & $4.2 \pm 0.5$ \\
\hline $37-25$ & $4.2 \pm 0.3$ & $8.8 \pm 0.9$ & $12.9 \pm 1.2$ & $10.7 \pm 1.1$ & $7.3 \pm 0.6$ \\
\hline $37-27$ & $3.5 \pm 0.4$ & $5.5 \pm 0.5$ & $5.8 \pm 0.5$ & $2.9 \pm 0.3$ & $1.8 \pm 0.2$ \\
\hline $37-31$ & $6.2 \pm 0.5$ & $10.8 \pm 1.0$ & $11.8 \pm 1.2$ & $7.9 \pm 0.7$ & $7.4 \pm 0.8$ \\
\hline
\end{tabular}

The results show that multiplication index changed depending the number of subcultures. In most hybrids, a gradual increase of this parameter to $3-4^{\text {th }}$ subcultures was observed. In the third subculture, the multiplication index reached 13.1; in the fourth -18.5 . In the 5- $6^{\text {th }}$ subcultures multiplication index decreased and did not exceed in the $6^{\text {th }}$ passage 8.7 (No. 37-14). The multiplication index in these passages for most of the hybrids was quite high and comparable or even higher in comparison with the cultivars or breeding samples of the essential oil rose [18]. Thus, in the cultivar 'Kazanlykskaya', this parameter in the $4^{\text {th }}$ passage reached a maximum value of 5.1. For many cultivars and samples of essential oil rose, earlier an increase of the multiplication index to the $3-4^{\text {th }}$ passages was also established. [18]. However, when analyzing $R$. damascena micropropagation, $\mathrm{Z}$. Jabbarzadeh and M. Khosh-Khui showed that the quantity of proliferating shoots in the first subculture was 4.6 times higher than in the fourth [10]. At the same time, for three cultivars of garden rose (Rosa hybrida), it was shown that the frequency of shoot multiplication was the greatest up to the $6^{\text {th }}-7^{\text {th }}$ subculture and thereafter, it declined [19].

Obtained in our experiments data on the change of the multiplication index during micropropagation of rose hybrids are comparable with the results for other plant species. An increase of multiplication index to the $3-5^{\text {th }}$ subcultures during in vitro propagation for some other essential oil plants, such as Origanum vulgare, Melissa officinalis [20], Lavandula angustifolia [21], was shown. For Vaccinium corymbosum it was also found that the fourth subculture gave the best results for multiplication [22]. 
A vital stage of micropropagation is the rooting of hybrid shoots in vitro. To induce root formation, we used previously optimized for essential oil rose medium ( $1 / 2$ MS with 0.5 mg/l NAA), on which the frequency of rhizogenesis in 5 studied cultivars varied from 85.7 to $100.0 \%$ [23]. However, when microshoots (obtained from hybrid seedlings) were cultivated on this medium, the root formation frequency in many genotypes was no more than $28.5-50.0 \%$ (Fig. 1). Only in No. 37-14, 37-21 and 37-24 from 68.4 to $100.0 \%$ of microshoots were rooted. Therefore, the influence of other modifications of MS medium on shoot rhizogenesis was analyzed. As can be seen from the presented data, for many hybrids (No. 37-2, 37-5, 37-11, 37-15, 37-20, 37-31), an increase of NAA concentration to $1.0 \mathrm{mg} / \mathrm{l}$ was effective. It allowed increasing the frequency of this parameter by 1.5-4.3 times. However, no rooting was detected in No. 37-25 on any of the tested media. The complexity of rooting during micropropagation of the essential oil rose in vitro was also indicated in several works $[1,7,10,14]$. Taking into account our data, for successful rooting of the obtained in embryoculture hybrids, it is advisable to use media of different composition.

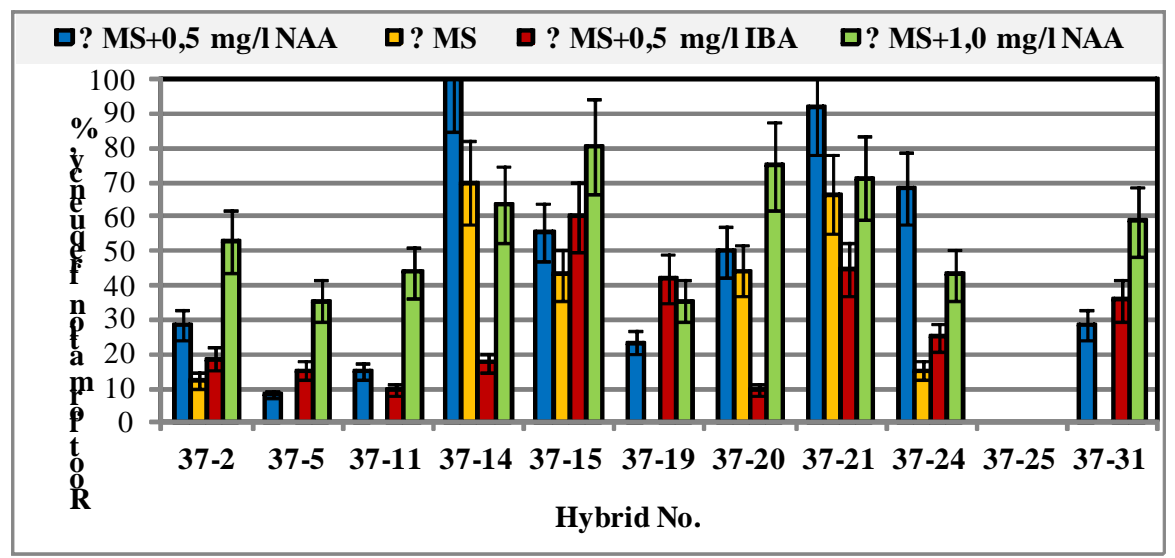

Fig 1. Influence of the culture medium composition on the root formation frequency (\%) in vitro during micropropagation of essential oil rose hybrids $(R$. alba $\times R$. damascena cv. 'Kazanlykskaya') obtained in embryoculture

Thus, as a result of the studies, significant variability of morphometric parameters during propagation and rooting in vitro of essential oil rose hybrids within the same crossing combination ( $R$. alba $\times R$. damascena cv. 'Kazanlykskaya') was demonstrated. Therefore, to obtain the required number of hybrids suitable for adaptation ex vitro, for different genotypes, it is advisable to use a different number of subcultures (microcuttings) and various culture media for the induction of rhizogenesis.

\section{References}

1. M. Khosh-Khui, International Journal of Horticultural Science and Technology, 1 (1) (2014)

2. A. Kumar, L. M. S. Palni, J. Hortic, Sci. Biotech., 78 (6) (2015)

3. M. Mahboubi, Journal of Traditional and Complementary Medicine 6 (2016)

4. V. S. Pashtetskii, N. V. Nevkrytaya, A. V. Mishnev, L. G. Nazarenko, Essential oil industry in the Crimea. Yesterday, today, tomorrow (Simferopol, Arial, 2018)

5. Ye. F. Semenova, Ye. V. Presnyakova, T. P. Zhuzhzhalova, Reproductive biology of species and forms of Rosa L. (Voronezh, Publ. CNTI, 2014) 
6. I.V. Stavtzeva, N.A. Yegorova Obtaining and propagation of essential oil rose hybrids in vitro. Guidelines (Simferopol: Publ. House IE Brazhnikov D.A., 2016)

7. H. M. Noodezh, A. Moieni, A. Baghizadeh, In Vitro Cell. Dev. Biol. Plant, 48 (6) (2012)

8. I. V. Mitrofanova, O. V. Mitrofanova, V. A. Brailko, N. P. Lesnikova-Sedoshenko, Applied Chemistry and Biotechnology, 2 (13) (2015)

9. S. Mirzaei, A. G. Zare, S. Jafary, International Journal of Environment, Agriculture and Biotechnology (IJEAB), 4 (5) (2019)

10. Z. Jabbarzadeh, M. Khosh-Khui, Sci. Hort., 105 (4) (2005)

11. A. Bosh, A. Moieni, H. Dehghani, Z. Movahedi, J. Plant Physiol. Breed., 6 (2) (2016)

12. V. Badzhelova, V. Bozhanova, Rastenievadni nauki, 55 (6) (2018)

13. A. Ginova, I. Tsvetkov, V. Kondakova, Bulg. J. Agric. Sci., 18 (4) (2012)

14. A. Nikbakht, M. Kafi, M. Mirmasoumi, M. Babalar, Int. J. Agric. Biol., 7 (4) (2005)

15. B. Allahverdi Mamaghani, M. Ghorbanli, M.H. Assareh, A. Ghamari Zare, Iran. J. Plant Physiol., 1(2) (2010)

16. K. Kshirsagar, V. J. Braganza, South Asian Journal of Experimental Biology, 2 (4) (2012)

17. M. Omidi, A. Yadollahi, E. Malihe, Biological Forum - An International Journal (BFIJ), 8 (1) (2016)

18. N. A. Yegorova, I. V. Stavtzeva, E3S Web of Conferences 224 (2020)

19. S. K. Senapati, G. R. Rout, Hort. Sci. (Prague), 35 (1) (2008)

20. N. A. Yegorova, O. V. Yakimova, Tomsk State University Journal of Biology, 47 (2019)

21. N. A. Yegorova, I. V. Mitrofanova, V. A. Brailko, O. A. Grebennikova, A. E. Paliy, I. V. Stavtseva, Russian Journal of Plant Physiology, 66 (2) (2019)

22. G. R. A. Mohamed, L. Z. Khusnetdinova, O. A. Timofeeva, Asian Journal of Plant Science and Research, 8 (5) (2018)

23. N. A. Yegorova, I. V. Stavtzeva, I. V. Mitrofanova, Biomics, 10 (1) (2018) 